\title{
Diglossia's Stability in the Arab World: Algeria as an Instance
}

\author{
Taoufik Djennane \\ Department of English, Tlemcen University, Algeria
}

\begin{abstract}
Built upon Ferguson's (1959/1972) and Fishman (1967) conceptualizations of diglossia, the present paper is dedicated to characterize diglossia in relation to Arabic. It is momentous to mention that, following several political, social, economic, and academic changes, the sociolinguistic situation in the, at least some, Arab nations does not seem to follow strictly Ferguson's original framework. The paper specifically inspects 'stability', one, out of nine, important rubric in the discussion of diglossia. To do so, Algeria is considered as a case in point. The discussion goes through the following stages: introduction of diglossia, characterization of diglossia in Algeria, then diglossia's stability.
\end{abstract}

Keywords: Arabic dialects, dialect promotion, polyglossia, stability, Standard Arabic, prestige.

\section{Introduction}

Although William Marçais [1] was the pioneer to introduce the term 'diglossie' to describe the linguistic situation in the Arab World (la diglossie arabe), diglossia as a sociolinguistic concept gained general currency with Ferguson [2] in his seminal article of 1959. Ferguson [3] used the term to refer to a situation where two varieties of a language exist side by side throughout the community, with each having a definite role to play. Explaining diglossia, Ferguson [2] identifies four speech communities: the Arab World, Greece, German-speaking Switzerland, and Haiti, considering them as being representative of the phenomenon. His definition makes a division between a High (henceforth $\mathrm{H}$ ) variety and a Low (hereafter $\mathrm{L}$ ) variety- both are linguistically related to, but significantly different from, one another. Therefore, diglossia is not bilingualism.

Ferguson [2] proceeds to explain the sociolinguistic condition under nine rubrics which are prioritised according to function, prestige, literary heritage, acquisition, standardization, stability, grammar, lexicon, and phonology. The functional linguistic distribution, or the specialisation of function, is the 'existential' feature of diglossia. The two discrepant varieties are kept separate and used in different settings and for different purposes. To characterise the $\mathrm{H}$ and $\mathrm{L}$ varieties does not pose a problem, suffice it to say that " $\mathrm{H}$ and $\mathrm{L}$ have disjoint functions: where $\mathrm{H}$ is appropriate, $\mathrm{L}$ is inappropriate and vice versa" (Sebba [4]).

What should be stressed is that Ferguson's conceptualization is not always valid nor it is enough comprehensive to cover all diglossic speech communities for it has a number of flaws which have since been pointed out. In some situations, the nine rubrics listed above meet what Ferguson suggests, in some others only some rubrics are met while the others are missed. For instance, when dealing with Fergusonian criterion of prestige in Switzerland, Hogg et al. [5] argue that we would maintain that High German is not afforded greater prestige or status than Swiss German, and therefore that German Switzerland does not constitute an example, or indeed defining case, of diglossia.

\section{Fishaman's Further Elaboration}

By 1967, Ferguson's original discussion had undergone some changes, when the American sociologist of language, Fishman [6], refined the definition in two basic directions:

1. While Ferguson restricts the concept only to two closely related varieties, Fishman proposes that diglossia may be extended to cover even situations where two (or more) genetically unrelated or at least historically distant language varieties occupy the $\mathrm{H}$ and $\mathrm{L}$ niches (Schiffman [7]). However, in such a situation Fishman emphasizes a tidy distinction between diglossia and bilingualism, arguing that the former is a feature of society to be dealt with by sociologists and sociolinguists, whereas the latter is a matter for psychologists and psycholinguists as it refers to an individual's ability to behave linguistically in more than one language.

2. Fishman also broadens the concept of diglossia to encompass even monolingual societies "which employ separate dialects, registers, or functionally differentiated language varieties of whatever kind." (Fishman $[8])$.

Under these two new guidelines, Fishman perceives diglossia in a spectrum ranging from two closely related varieties, along with different stylistic differences, to two (or more) completely distant languages. This further consideration is referred to as extended diglossia. However, not all scholars share the view with Fishman as far as the second point (monolingual speech communities) is concerned. What is worth considering is that both Ferguson and Fishman share a common view as far as the functional specialization is concerned. Both 
insist on the core theoretical claim, with $\mathrm{H}$ being reserved for formal contexts and $\mathrm{L}$ designed for informal purposes.

\section{Characterizing Diglossia In Algeria}

Belonging to the Arabic-speaking World, Algeria, being in no way the exception, is a de facto diglossic community. In classical terms, i.e. Ferguson's description [2], Standard Arabic, SA for short, has the H stand and function, whereas Algerian Arabic (hereafter AA), a number of mutually intelligible regional dialects represents the L variety (what is said about Algeria as far as Standard Arabic and Algerian Arabic are concerned perfectly applies to most other Arabic-speaking countries). SA, being constitutionally recognised as the sole official language of the State, is allocated to formal usage. It is employed in literacy and for literary purposes, delivering religious preaches, broadcasting news and so forth. AA is ascribed to informality, typically used in casual conversations and daily interaction. It is also used in folk literature, informal TV and radio programmes (soaps), in captions and caricature on political cartoons in newspapers, and also in advertising. However, it is of significance to mention that overlaps that nullify the complementary distribution of SA and AA are abundant in that $\mathrm{H}$ and $\mathrm{L}$ are not always kept separate. For example, in an informal context such as a family meeting, though AA is undoubtedly the prevalent variety, if a topic including, for example, science is to be discussed, SA would be extensively used for the simple reason that education is conducted in SA. AA lacks scientific terms and therefore speakers find it a necessity to code-switch back and forth between the $\mathrm{H}$ and $\mathrm{L}$ so as to compensate for such a linguistic gap. Again, while Ferguson insists that the function dictates the choice of the linguistic variety, counter examples are ample. Ferguson [2] claims that political speech is presented in $\mathrm{H}$, but it actually appears in the two forms of Arabic. Many times, politicians, be competent or not in SA, favour AA to address the mass as they see AA the language of the people and hence more appropriate to get the message across.

Regarding prestige, SA is perceived as a superposed variety and seen as the correct language. The high prestige it enjoys is due to its direct relation with the Quran (Muslims Holy book) and a number of religious texts making it a venerated and sacred language. It is also highly valued by virtue of its association with a bulk of literature ranging from the most traditional pre-Islamic poetry to the very contemporary writings. On the other hand, though AA is the natural spoken vehicle in the home and the street, it is often referred to as dialect, colloquial or vernacular, and felt to be less worthy, simply an aberration of the norm. It is not uncommon to hear someone saying: [ka:n jahdar balluya], to mean 'he was using the language'. The word [alluya] ('language'), which means in this context 'the standard form', is reserved only to the highly esteemed variety (SA). These attitudes remain societal judgments and perceptions, however. It follows that, on linguistic grounds, all varieties have the same footing as far as they fulfill communicative tasks.

Again, like other diglossic communities, SA is the native tongue of no sector in the society. It is a 'learned' form accessible through schooling. In other words, those who do not attend school or any kind of educational institutions such as alkuttab (a religious school) generally will not have access to SA. This is in sharp contrast with some Western societies, like France, England, and Germany ('standard-with-dialect' contexts), where the Standard variety is acquired as the mother language by a significant portion of the total population.

Another crucial point is that SA is more stable, being protected from change as a result of its association with writing and education. AA is more localized and displays dialectal variations, however.

Since Algeria is a linguistic market where at least three languages, namely Arabic, Berber and French compete one another in various domains and in different regions making societal multilingualism the general condition rather than the exception, Algeria not only represents classic diglossia but is also a defining case of extended diglossia. The rationale for this is that French, though it has no constitutional stand, is a functioning language that fulfills formal and official linguistic tasks along with SA. Considering higher education as an instance, French is indeed the medium of instruction in a number of faculties in the Algerian university. Lectures in technical and scientific majors, such as civil engineering, architecture, computer sciences, biology, etc, are all exclusively conducted in French. In such contexts, French is allocated to formal usage, namely the classroom interaction and thus has the $\mathrm{H}$ function; Algerian Arabic is the L variety used amongst students outside the classroom in natural interactions. It should be noted here that if SA is to be regarded vis à vis French, both are considered $\mathrm{H}$ varieties with high prestige (bilingualism in such a situation). If teaching in scientific and technical fields is done in French, SA is the medium of instruction in other fields, such as commerce, economy, law, etc. And thus the H-L relationship is to be considered with regard to AA instead of SA. Beyond the educational sphere, the Algerian speech community is practically bilingual and speakers use Arabic, whether Standard or dialectal, and French according to their assigned functions and prestige. Algeria thus provides an illustration of what Fishman [6] calls in his theoretical construction 'diglossia with bilingualism' at the national level.

In fact, diglossia in Algeria also deserves to be discussed in relation to Berber, or as they are locally called Amazigh, communities since the Berber/Tamazight language has recently (2002) gained the status of 
'national' language. In such communities, like Great Kabylia, Shaouia, Beni Mzab, etc, 'extended triglossia' is a widespread phenomenon. SA and French, like the rest of the country, are used in government official domains, administration and education, whereas Kabylie, Shaoui and Mzabi, Berber varieties that are historically distant to Arabic and French, play the role of the L variety being the natural everyday communication vehicles. Here, it is of prime importance to mention that attitudes toward SA or French may differ among individuals, and there is no guarantee that they are perceived as the superposed, prestigious varieties.

In sum, the following diagram provides a simple, yet interesting, characterization of diglossia in Algeria:

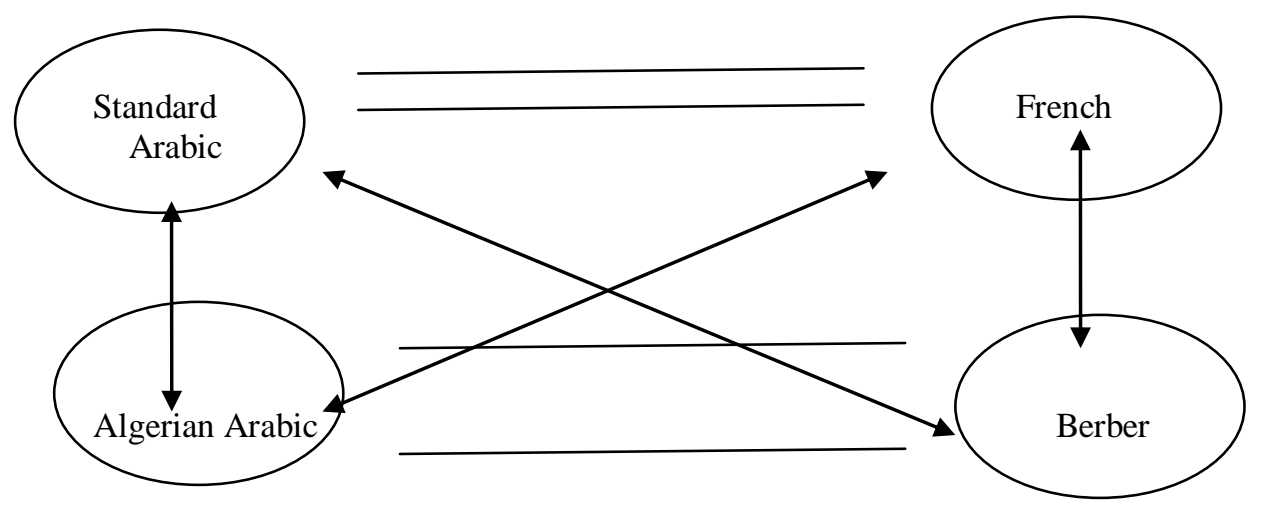

Figure 1. Characterization of diglossia in Algeria

The above mentioned figure reveals an interesting fact: (1) classic diglossia is commonly attested in Arabophone regions with regard to SA and AA; (2) again, extended diglossia concerns basically Arabophone areas where French (and also SA) is the H variety and AA is the L variety; (3) extended triglossia is a unique feature of Berberophone regions where both SA and French represent $\mathrm{H}$ and Berber is the de facto L variety; (4) Algerian Arabic is also used in Berberophone areas either for local communication or typically for interaction with Arabophone speakers, such as in commerce- This is a form of bidialectalism; (5) though French may also be used in informal contexts, such as the street and the family, both SA and French are regarded as $\mathrm{H}$ varieties that hold high esteem (of course this can also be interpreted as a form of societal bilingualism).

Under a number of circumstances, the designation 'stability', which constitutes one rubric in Ferguson's [2] discussion, seems to follow new directions as it will be shown below.

\section{Diglossia's Stability}

Ferguson's [2] [3] definition of diglossia assumes that it is a relatively stable language situation. Diglossia is not ephemeral in nature, according to Wardhaugh [9], but it appears to be a persistent social and linguistic phenomenon. However, under a number of political, social, economic, and academic pressures, the stability of diglossia seems to be disturbed. What follows represents the chief outstanding burdens:

1. Ferguson [3] points out that the highly people are accustomed to ' $\mathrm{H}$ ' and the more frequently they use it, the stronger a blurring of the linguistic differences between ' $\mathrm{H}$ ' and ' $\mathrm{L}$ ' is likely to occur. In Algeria, the free, compulsory education offered by the government, reinforced by the Arabisation Policy applied since the 1970s to replace French (a language policy which imposes Arabic as the sole official language), has started to pick up its harvest. Now, it is in no way odd to hear people alternating between SA and AA in the course of a single conversation. Such linguistic behaviour is the byproduct of increased familiarity with SA, as the ratio of illiteracy is in continuous decrease. Switching between the two varieties is a linguistic tool people tend to employ particularly when they engage in conversations that include new concepts or lexical items that have no dialectal equivalents making it a necessity to switch to the language on instruction (SA) - such a linguistic behaviour may be accounted for in terms of diglossic switching which is contrasted with cross-linguistic switching that involves alternating between two different languages. Then, the media is also widely arabised. Such communication means represent an important window for the diffusion of SA. It has also become very common to hear, in a semi-formal encounter (e.g. TV interviews), educated speakers mixing the acrolect (SA) and the basilelect (AA), i.e., using an admixture. This is a form which is now largely referred to as 'Educated Spoken Arabic'.

2. The rise of English as a global language has had its influence. English is now a significant language, a language of diplomacy, science, technology and commerce. In Algeria, English is politically regarded a (second) foreign language and its use is very limited. However, in recent years it has been introduced as a compulsory subject to first year middle school learners. It is also greatly encouraged in higher education, and any researcher is now asked to give a summary of the research in English. These sociopolitical changes may 
along the line allow it gain ground and be introduced as a functioning language that fulfills official domains. Subsequently, polyglossia, instead of diglossia, will be by then the prevalent sociolinguistic phenomenon.

3. The promotion of nationalism, in contrast to nationism, is also a serious factor that may cause diglossia's disappearance. In the Middle East, proponents of, for example, Cairene Arabic and Damascene Arabic regard such varieties as symbols of national affiliation and hence more accurate national languages for Egypt and Syria respectively than SA which is in fact a lingua franca shared by all the Arab World. A noticeable feature is that previously (approximately toward the end of the millennium) all movies, series, TV shows, etc, imported from non-Arabic-speaking countries, when translated, were all presented on the TV in SA. Now, with increased desire for promoting national languages, many of such programmes appear in the local vernaculars. Turkish series, which have a huge number of fans in the Arab World, are currently presented in Lebanese Arabic; some cartoons are delivered in Egyptian Arabic; and still a number of Mexican and Turkish series appear in Moroccan Arabic. The point here is that SA may undergo a process of language shift if the Arab nations manage to standardize their local dialects. Having one language in common has a number of advantages, not least a perfect communication from Morocco to Iraq. At the same time, losing that language would have strong impacts at many levels: social, cultural, economic, etc. The situation would best be compared to that of Latin. The rise of nationalism in France, Italy, Spain, Portugal, and ex Latin-speaking countries led to the promotion of local varieties in these States, resulting in what is now known as Romance languages. Latin, which was at a point the superposed variety and the language of literacy and science, is now a language reserved mainly to liturgical purposes in churches.

The other crucial point is made upon academic bases. The fact that SA (as an instance of all ' $\mathrm{H}$ ' varieties in most diglossic communities) is the mother tongue of no sector in the community, and that children become aware of it until school age, while colloquial Arabic, though highly stigmatized, is the genuine mother tongue acquired first and being used on a daily basis, has urged some linguists and language educators to put forward that SA should not be promoted by education systems in and outside the Arab World. For many researchers, low literacy rates in the Arab world are a direct outcome of the diglossic nature of Arabic. This is made on the claim that the best way for an efficient literacy is via the first language. A number of proposals have been suggested to cope with the situation but no consensus could be met. Palmer [10], for instance, when talking about Arabic programs in the USA, supports the idea that such programs must promote the teaching of spoken Arabic into their curricula. Such a view is made upon the point that the standard language creates a fake model of oral proficiency by presenting the students with an artificial variety that is not used by the native speakers for daily-life communication. By the same token, in discussing the teaching of Arabic to foreign learners, Younes [11] proposes that students should be introduced to both a spoken Arabic dialect and formal Arabic from the beginning of an Arabic course if they hope to function competently in Arabic. The question which posits itself is what dialectal Arabic should be taught?

Upgrading dialectal Arabic in the Arab World, if it is to be implemented, is no easy task. Such a procedure makes it a must to pass through a whole language planning process. First, in terms of status planning, which regional variety to choose? Although they constitute a dialectal continuum, every Arab State has a number of regional dialects, each with specific linguistic traits to the extent that mutual intelligibility is sometimes deeply affected within the same country. Though language determination (status) is basically policydriven, it is an act that may generate a lot of problems among the population and lead to social upheavals for it is not easy to accept the variety of another group to be favored and therefore codified then imposed on the whole community. Secondly, in terms of corpus planning, which accent should enjoy high esteem? Which syntactic structures and morphological forms are to be permitted? Which regional items are to be favored? Finally, as far as language in education policy (acquisition planning) is concerned, can the prerequisites Bowers [12] proposes (basic teaching and reading materials, accepted writing system, and teachers who master that variety) be met? Even if such necessities are available, it is a fact that people in general perceive the spoken variety to be less prestigious and less worthy. In this respect, Versteegh [13] argues that it remains difficult in the Arab world to arouse interest in the dialects as a serious object of study. Many speakers of Arabic still feel that the dialect is a variety of language without a grammar and even in the universities there is a certain reluctance to accept dialect studies as a dissertation subject".

\section{Conclusion}

What is evident is that there is no chance for any colloquial Arabic to be the ' $\mathrm{H}$ ' variety as long as SA is politically promoted and protected. In Algeria, the standard form still has the highest regard, and it is constitutionally preserved and explicitly declared as the sole official language of the State. Thus, one should wonder whether such a procedure, which demands linguistically sophisticated experts and a considerable political endeavour, is necessary or not. For it is a highly complex process that may span centuries, why not to think the other way round, that is increasing the use of Standard Arabic even colloquially beginning from the home. If this is to be encouraged and forced, the time-depth factor may lead to a standard-with-dialect 
community. The rationale for this is that most world languages were only dialects. Through a process of standardization, which Haugen [14] sees as selection of a norm, codification, elaboration of function, and acceptance, such dialects were politically favored and hence imposed at a national level to serve as a unifying force. Now, in France, England, Germany, and so forth, significant portions of the population acquire French, English, and German, respectively as their mother tongue, although various dialects still exist in such countries.

\section{Références}

[1] W. Marçais, La diglossie arabe, L'Enseignement Public, 97, 1930, 401- 409

[2] C. A. Ferguson, Diglossia, in D.Hymes (Ed.), Language in Culture and Society, (New York: Harper \& Row, 1964) 429-39.

[3] C. A. Ferguson, Diglossia, in Gigliolo (Ed.), Language and social context. Selected readings, ( Harmondsworth, 1972) $232-251$.

[4] M. Sebba, Societal bilingualism, in R.Wodak, B. Johnstone, P.Kerswill (Ed.), The handbook of sociolinguistics, (Los Angeles, London, 2011) 445-459.

[5] M. Hogg, N. Joyce, D. Abrams, Diglossia in Switzerland? A social identity analysis of speaker evaluations, Journal of Language and Social Psychology, 3,1984, 185-196.

[6] J. A. Fishman, Bilingualism with and without diglossia; diglossia with and without bilingualism, Journal of Social Issues, 32, 1967, 29-38.

[7] H. Schiffman, Diglossia as a sociolinguistic situation (Pennsylvania: University of Pennsylvania, 2004).

[8] J. A. Fishman, The sociology of language: An interdisciplinary social science approach to language in society (Rowley, 1972).

[9] R. Wardhaugh, An introduction to sociolinguistics (Blackwell Publishing. 2006).

[10] J. Palmer, Arabic Diglossia: Teaching Only The Standard Variety Is A Disservice To Students, Arizona Working Papers in SLAT, $14,2007$.

[11] M. A. Younes, An integrated curriculum for elementary Arabic, in M. Al-Batal (Ed.), The teaching of Arabic as a foreign language: Issues and directions, (Provo, Utah: American Association of Teachers of Arabic, 1995) 233-255.

[12] J. Bowers, Language problems and literacy, in J, Fishman, C. Ferguson, J. Das Cupta (Ed.), Language Problems and Developing Nations, (New York: John Wilers and Son, 1968).

[13] K. Versteegh, The Arabic language (Edinburgh: Edinburgh University Press, 2004).

[14] E. Haugen, Dialect, Language, Nation, American Anthropologist, 68, 1966, 922-35. 